\title{
Performance of Vetiver Grass (Vetiveria zizanioides) for Phytoremediation of Contaminated Water
}

\author{
Sharifah Nur Munirah Syed Hasan ${ }^{1}$, Faradiella Mohd Kusin ${ }^{1 *}$, Ashton Lim Sue Lee ${ }^{1}$, Tony \\ Austin Ukang ${ }^{1}$, Ferdaus Mohamat Yusuff ${ }^{1}$, and Zelina Zaiton Ibrahim ${ }^{1}$ \\ ${ }^{1}$ Department of Environmental Sciences, Faculty of Environmental Studies, Universiti Putra \\ Malaysia, 43400 UPM Serdang, Selangor, Malaysia
}

\begin{abstract}
In tolerance towards metal uptake, there is a need to evaluate the performance of vetiver grass for metal removal to reduce water impurity. This study was aimed to evaluate contaminant removal by vetiver grass at varying root length and plant density and determine the metal uptake in vetiver plant biomass. Pollutant uptake of vetiver grass was conducted in laboratory experiment and heavy metal analysis was done using acid digestion and Atomic Absorption Spectrometry. Findings indicated that the removal of heavy metal was decreased in seven days of the experiment where iron shows the highest percentage $(96 \% ; 0.42 \mathrm{ppm})$ of removal due to iron is highly required for growth of vetiver grass. Removal rate of heavy metals in water by vetiver grass is ranked in the order of $\mathrm{Fe}>\mathrm{Zn}>\mathrm{Pb}>\mathrm{Mn}>\mathrm{Cu}$. Results also demonstrated greater removal of heavy metals $(\mathrm{Cu}, \mathrm{Fe}, \mathrm{Mn}, \mathrm{Pb}, \mathrm{Zn})$ at greater root length and higher density of vetiver grass because it increased the surface area for metal absorption by plant root into vetiver plant from contaminated water. However, findings indicated that accumulation of heavy metals in plant biomass was higher in vetiver shoot than in root due to metal translocation from root to the shoot. Therefore, the findings have shown effective performance of vetiver grass for metal removal in the phytoremediation of contaminated water.
\end{abstract}

\section{Introduction}

Vetiver grass (Vetiveria zizanioides) has been identified as the potential plant to be used in the phytoremediation treatment. Vetiver grass (VG) is a tall $(1-2 \mathrm{~m})$, fast-growing, perennial tussock grass. It has a long (3-4 m), massive and complex root system, which can penetrate to the deeper layers of the soil [1-4]. The dense high fiber, fine root system that forms an enormous volume accelerates habitat for many symbiotic bacteria, and fungi made the ecology system naturally contributes to the pollutant uptake. Furthermore, VG has ability to absorb large amounts of environmental pollutants such as heavy metals,

\footnotetext{
* Corresponding author: faradiella@upm.edu.my
} 
pesticides/herbicides and petroleum hydrocarbon without effect its growth [5]. Through these characteristics, VG can be used for purification of polluted sites and normalised the eutrophic areas.

In addition, $\mathrm{VG}$ also involve in translocation process to uptake the contaminant by using plants roots which act as phytoextraction $[4,7]$. The rate of phytoextraction depends on the root depth in soil or medium because root acts as the metal accumulator $[4,8]$. This application is almost similar to rhizofiltration but it is normally used on groundwater, wastewater and surface water as hydroponic treatment; because the root can come in contact with water $[9,10]$. The process occurs during the adsorption of contaminants onto root surface or plant root absorption. Thus, the plant root is responsible to accumulate the heavy metal with the application of plant translocation.

Another unique characteristic of $\mathrm{VG}$ is that it has high tolerance to elevated concentrations of heavy metals such as $\mathrm{As}, \mathrm{Cd}, \mathrm{Cu}, \mathrm{Cr}, \mathrm{Pb}, \mathrm{Hg}, \mathrm{Ni}, \mathrm{Se}$ and $\mathrm{Zn}$ in the soil [1, $11,12]$. Besides, VG has high tolerance and adaptability to extreme edaphic conditions such as soil with high acidity and alkalinity. It can thrive under a wide $\mathrm{pH}$ range and adapt to saline, sodic and magnesic conditions, and aluminium and manganese toxicities $[7,11$, 13]. VG also can survive between $\mathrm{pH} 3.3$ to 9.5 at nutrient-adequate condition and saline soil with high electrical conductivity up to $4.0[1,10,13,14]$. Therefore, the outstanding morphological and physiological features of VG make it suitable choice for water treatment purposes.

Lack of previous research discover the potential of $\mathrm{VG}$ in removal of heavy metal for phytoremediation especially in polluted running water. In this study, treatment using phytoremediation of VG was applied in removing or controlling various types of pollutants from contaminated water. The objectives of this study are to evaluate contaminant removal by VG at different root length and plant density and also to determine the metal uptake in vetiver plant biomass.

\section{Materials and methods}

\subsection{Testing of vetiver grass performance}

\subsubsection{Experimental works}

The experimental works were carried out as a platform for more complex analytical conditions on vegetative, physical and physico-chemical parameter measurements. The conditions at actual site was simulated in the laboratory and therefore experiment was undertaken in seven days of period under controlled environment through continuous flow experiment (Fig. 1). The laboratory experiment of VG performance on pollutant uptake were carried out by planting VG at different root length $(10 \mathrm{~cm}, 20 \mathrm{~cm}, 30 \mathrm{~cm})$ and plant density (4 tillers, 10 tillers) that has been trimmed accordingly to given root length and density in hydroponic system. However, the tillers that were too young was ignored and not counted as a tiller. 

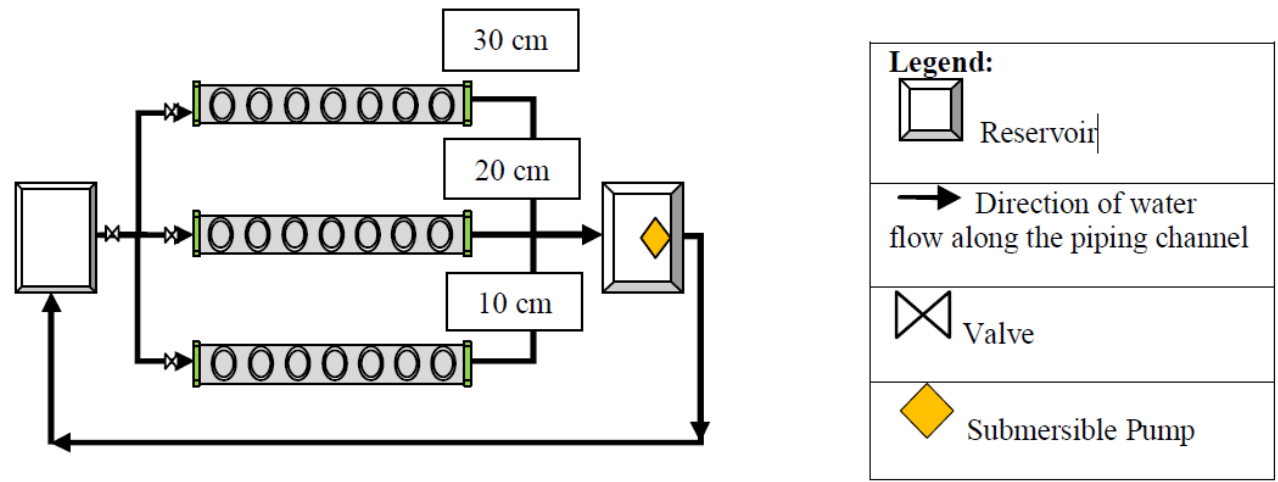

Fig. 1. Example of a set of hydroponic system (plan view).

\subsection{Performance of vetiver grass for phytoremediation technique}

\subsubsection{Vetiver grass planting}

The plants (vetiver grass) were obtained from local suppliers and were typically delivered as young vetiver in boxes (200 tillers of VG in each box). For the purpose of young vetiver planting in water medium, the soil is washed off in order for the plant to adapt to the environment prior to the planting. The plants were kept afloat in the container with the crowns above the water surface (Fig. 2).

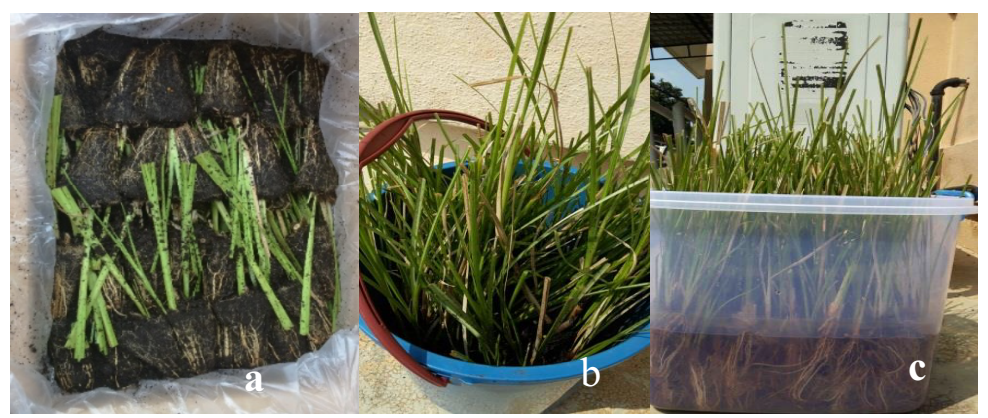

Fig. 2. (a) Young plants in the box (b) Plants being soaked in a pail of water to loosen up the soil before washing (c) Make sure to keep the crown above water surface.

Note: Make sure that the crown is not soaked in the water as it would damage the crown, which in turn, killing the plants.

Then, the VGs were transferred to the containers for plant acclimatization and growth of the root length. Hydroponic solution of (N6: P3: K10 + Ca $+\mathrm{Mg}$ ) was added one week after the plant acclimatization in tap water to assist in the growing process. 


\subsection{Heavy metal uptake by vetiver grass in static condition}

\subsubsection{Water sampling}

The experiment was conducted for 10 days to observe the effect of root length and plant density on contaminant removal. The initial concentration was set to be $10 \mathrm{ppm}$ for all five heavy metals which are copper $(\mathrm{Cu})$, iron $(\mathrm{Fe})$, manganese $(\mathrm{Mn})$, lead $(\mathrm{Pb})$ and zinc $(\mathrm{Zn})$ based on the worst case scenario of heavy metal occurrence found in Malaysia $[15,16,17]$.

The water sampling was conducted every day which involved in-situ and ex-situ. The in-situ parameters such as $\mathrm{pH}$, temperature, electrical conductivity (EC), and salinity were recorded, while the ex-situ parameter was done through the analysis of heavy metals uptake by VG in water and plant biomass such as root and shoot. $50-\mathrm{mL}$ of water sample was taken, placed in a centrifuge tube and were filtered using $0.45 \mu \mathrm{m}$ cellulose acetate filter paper to remove large biological materials. Then, the water samples were acidified to $\mathrm{pH}<$ 2 by addition of $0.7-\mathrm{ml}$ of nitric acid $\left(\mathrm{HNO}_{3}\right)$ Suprapur $65 \%$.

\subsubsection{Plant harvesting}

Plants biomass was separated in two samples which contain of shoots and roots. The vetiver shoots and roots were dried at $70-85^{\circ} \mathrm{C}$ in the oven to a constant weight and the total harvestable dry biomass production was then determined via dry weight of each sample. Then, $0.1 \mathrm{~g}$ of shoots and roots are grinded using mortar and pestle and was digested with $10 \mathrm{~mL}$ of $65 \% \mathrm{HNO}_{3}$ (AR grade; $\mathrm{BDH}$ ). The acid digestion was prepared using a digestion block at $90^{\circ} \mathrm{C}$ and it was then cooled at room temperature. The digestate sample was filtered using $0.45 \mu \mathrm{m}$ cellulose acetate filter paper by syringe filter. Digested vetiver samples were analyzed using Atomic Absorption Spectrometry (AAS model AA-6800 Shimadzu) to determine concentration of heavy metal in shoots and roots.

\subsection{Data analysis}

The removal efficiency of each heavy metal was calculated to determine the potential of heavy metal uptake of VG based on following equation [19]:

\% Removal efficiency $=\frac{(C \text { ini }- \text { C fin })}{C \text { ini }} \times 100$

where Cini represent the initial concentration of metal content, while $\mathrm{C}_{\text {fin }}$ signify the final concentration of metal content.

\section{Results and discussion}

\subsection{Heavy metal removal by vetiver grass}

General trend shows that the concentration of all pollutant $(\mathrm{Cu}, \mathrm{Fe}, \mathrm{Mn}, \mathrm{Pb}, \mathrm{Zn})$ were decreased from day one up to day seven of the experiment. Fig. 3 shows that the highest percent of metal removal was iron $(96 \% ; 0.42 \mathrm{ppm})$, followed by zinc $(75 \% ; 2.55 \mathrm{ppm})$, lead $(50 \% ; 4.97 \mathrm{ppm})$, manganese $(33 \% ; 6.71 \mathrm{ppm})$ and the least removal was copper $(25 \% ; 7.47 \mathrm{ppm})$ in seven days of period. The findings were in line with previous studies that iron $(\mathrm{Fe})$ had high removal compared to other heavy metals $[7,18]$. This is because the 
growth of VG requires high uptake of Fe and other macronutrient such as nitrogen $(\mathrm{N})$, phosphorus $(\mathrm{P})$ and potassium $(\mathrm{K})$ by the root and also for photosynthesis reactions $[5,19]$. Within seven days, uptake of heavy metal are differ due to its high tolerance towards elevated concentrations of heavy metal. It is suggested that VG required a longer time (more than a week) to absorb other heavy metals such as $\mathrm{Pb}, \mathrm{Mn}$ and $\mathrm{Cu}$ that are not essential for vetiver growth. This indicated that VG have great ability in removing heavy metal within a short days of period. Thus, it can be seen that the percentage removal of heavy metal is ranked in the order: $\mathrm{Fe}>\mathrm{Zn}>\mathrm{Pb}>\mathrm{Mn}>\mathrm{Cu}$.

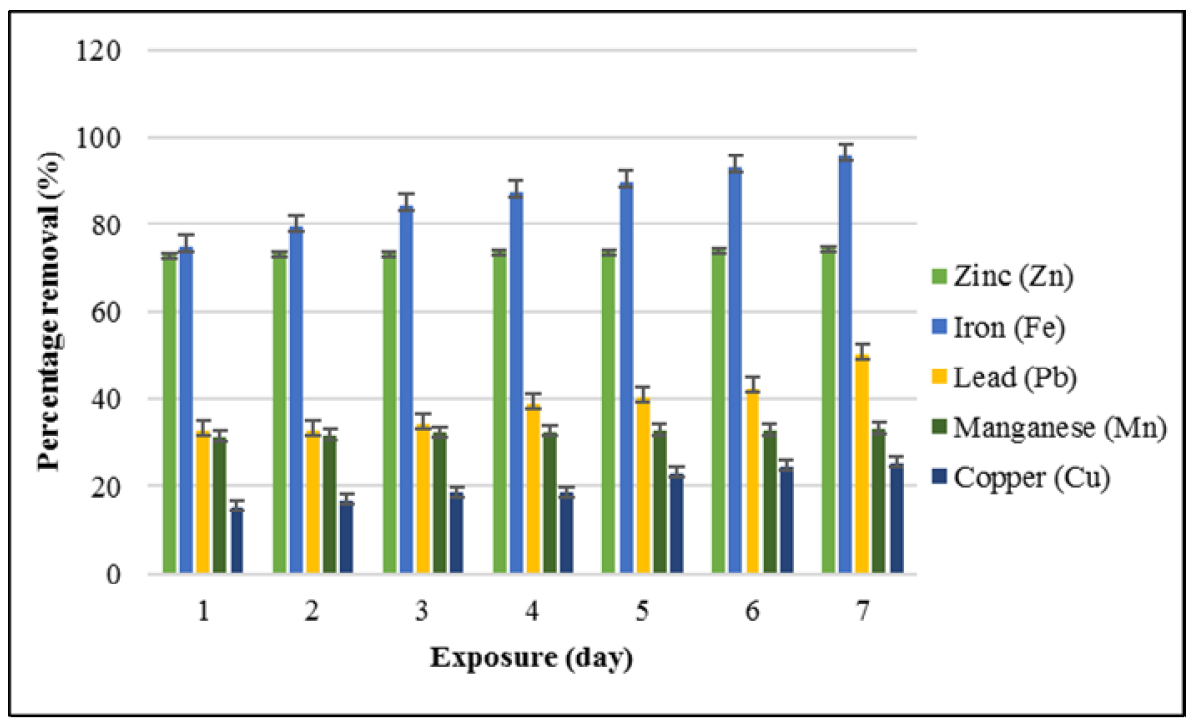

Fig. 3. Percentage of heavy metals removal (\%) by vetiver grass within 7 days of experiment.

In general, greater removal of all heavy metal was found at greater root length and higher density with different metal concentration. Results show that most of heavy metals were being removed at a very fast rate for concentration less than $2 \mathrm{ppm}$ and $\mathrm{Fe}$ has the highest removal at both four vetiver tillers (Fig. 4a) and 10 vetiver tillers (Fig. 4b). Findings indicated that large number of vetiver tillers used can increase the removal of heavy metals as the concentration rises. When density (number of vetiver tillers) increases, removal of heavy metal also increases. By the end of four days, most of the heavy metals were already taken up by the plants. This might due to higher surface area from many plants that can absorb large amount of heavy metals from metal concentration [19, 20]. The removal among heavy metals in water regardless of their density can be ranked in the order of $\mathrm{Fe}>\mathrm{Zn}>\mathrm{Pb}>\mathrm{Cu}>\mathrm{Mn}$. Therefore, number of vetiver tillers used is one of the important factors that has significant role in reducing heavy metal contents especially in metalcontaminated water. 

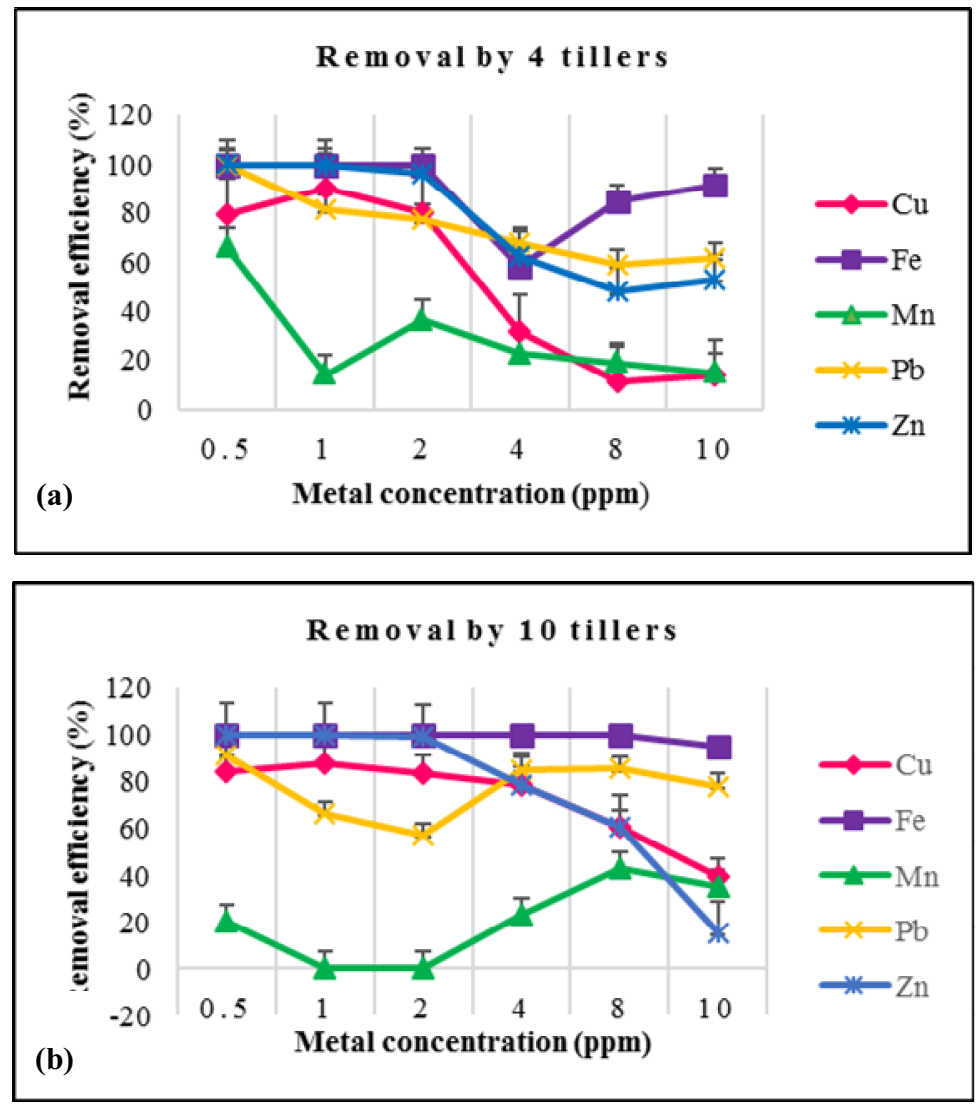

Fig. 4. Heavy metals $(\mathrm{Cu}, \mathrm{Fe}, \mathrm{Mn}, \mathrm{Pb}, \mathrm{Zn})$ removal after four days by 4 vetiver tillers (a) and 10 vetiver tillers (b)

\subsection{Metal accumulation in plant biomass}

Overall, the plant biomass accumulation is notably higher at greater root length, while higher metal accumulation was found in shoot compared to the root (Fig. 5). The metals uptake by plant biomass in root was found higher at $30 \mathrm{~cm}$ of root length (Fig.5a). Findings indicated that the longer the root length, the higher accumulation of metals. This is because greater root length has higher surface area for metal absorption by the root into the plants from polluted water $[19,20]$. Besides, its complex and massive vetiver root system encouraged the potential of high amount of metals uptake at different root length [1-4]. Thus, the vetiver root length is a good metal-accumulator due to its ability in taking up excessive amount of pollutant contents in polluted water.

However, result shows that metal accumulation was higher in shoot than in root (Fig. 5 b). Current findings contradict the previous research where plant root uptake high amount of metal contents compared to the shoot $[18,21]$. This is because of metals translocation from root to shoot which results in high accumulation of heavy metals in the shoot $[4,5,8]$. This suggests that plant root can uptake high metal contents during the early stage of the experiment and resulting in high accumulation of metals occurred at plant shoot. Therefore, current findings have shown the unique physiological features of VG in tolerance towards 
metal-accumulation and translocation of heavy metals from water into plant biomass at different root lengths.
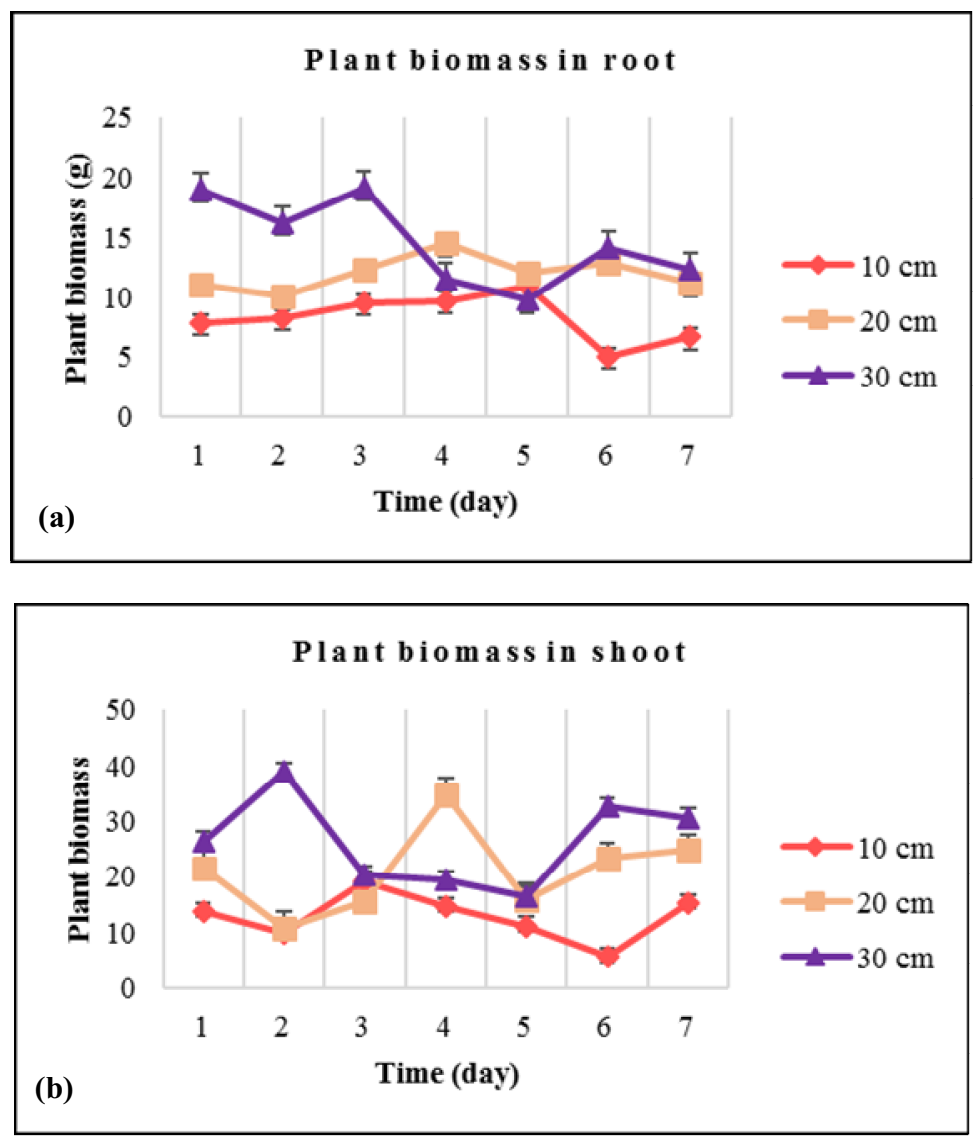

Fig. 5. Plant biomass in root (a) and shoot (b) at different root lengths.

\section{Conclusion}

Vetiver grass is a good accumulator of heavy metals in phytoremediation due to great ability in absorption of metals in water except for $\mathrm{Mn}$ and $\mathrm{Zn}$. All the heavy metal elements have shown decreasing trends of metal concentration at different root length and density. Longer plant root length and higher vetiver density increased the uptake of heavy metals in polluted water. Metal accumulation occurred at both vetiver root and shoot but greater in shoot due to translocation of heavy metals from root to shoot.

The research was supported by Humid Tropic Centre (HTC), Department of Irrigation and Drainage (DID) Malaysia, Humibox (M) Sdn. Bhd. as a supplier for the vetiver grass and Faculty of Environmental Studies, Universiti Putra Malaysia for providing facilities. 


\section{References}

[1] L.T. Danh, P. Truong, R. Mammucari, T. Tran and N. Foster, Vetiver grass, Vetiveria zizanioides: a choice plant for phytoremediation of heavy metals and organic wastes, Int. J. of Phytoremediation, 11, 664-691 (2009)

[2] N.M.R. Pichai, R. Samjiamjiaras and H. Thammanoon, Vetiver and its multifold applications, Asian Infrastruct. Res. Rev., 3, 1-4 (2001)

[3] P.A. Dalton, R.J. Smith and P.N.V. Truong, Vetiver grass hedges for erosion control on a cropped flood plain: hedge hydraulics, Agr. Water Manage., 31, 91-104 (1996)

[4] P.N. Truong, Vetiver grass technology for environmental protection, Proc. of the Second Int. Vetiver Conf., Bangkok, Thailand, (2000)

[5] N. Roongtanakiat and P. Chairoj, Uptake potential of some heavy metals by vetiver grass, Kasersart J. (Nat. Sci.), 35, 46-50 (2001)

[6] D.E. Salt, M. Blaylock, N.P.B.A. Kumar, V. Dushenkov, B.D. Ensley, I. Chet and I. Raskin, Phytoremediation: a novel strategy for the removal of toxic metals from the environment using plants, Biotechnology, 13(5), 174-468 (1995)

[7] P.N. Truong, Y.K. Foong, M. Guthrie and Y.T. Hung, Phytoremediation of heavy metal contaminated soils and water using vetiver grass, Environ. Bioengineering, 11, 233-275 (2010)

[8] S. Kidney, Phytoremediation may take root in Brownfields, The Brownfields Report, 2(14), 1-6 (1997)

[9] National Risk Management Research Laboratory (NRMRL), Environment Protection Agency (2000)

[10]F.M. Kusin, A review of the importance of hydraulic residence time on improved design of mine water treatment systems, World Appl. Sci., 26(10), 1316-1322 (2013)

[11]N. Chomchalow, The role of vetiver in controlling water quantity and treating water quality: an overview with special reference to Thailand, The Fourth Thai Nat. Conf. on Vetiver, Bangkok, Thailand, AU J.T., 6(3), 145-161 (2003)

[12] W.S. Shu, Exploring the potential utilization of vetiver in treating acid mine drainage (AMD), Proc. of the Third Int. Vetiver Conf., Guangzhou, China, (2003)

[13]F.M. Kusin, A.P. Jarvis and C.J. Gandy, Hydraulic performance and iron removal in wetlands and lagoons treating ferruginous coal mine waters, Wetlands, 34(3), 555-564 (2014)

[14]R. Webb, The Permaculture Research Institute, Vetiver grass - a hedge against erosion, (2009), Retrieved on June 15, 2015 from http://permaculturenews.org

[15] M.V. Prasanna, S.M. Praveena, S. Chidambaram, R. Nagarajan and A. Elayaraja, Evaluation of water quality pollution indices for heavy metal contamination monitoring: a case study from Curtin Lake, Miri City, East Malaysia, Environ. Earth Sci., 67, 1987-2001 (2012)

[16]H. Hatar, S.A. Rahim, W.M. Razi and F.K. Sahrani, Heavy metals content in acid mine drainage at abandoned and active mining area, AIP Conf. Proc., 1571, 641-646 (2013)

[17] T. Hadibarata, F. Abdullah, A.R.M. Yusoff, R. Ismail, S. Azman and N. Adnan, Correlation study between land use, water quality, and heavy metals $(\mathrm{Cd}, \mathrm{Pb}$, and $\mathrm{Zn})$ content in water and green lipped mussels Perna viridis (Linnaeus.) at the Johor Strait, Water Air Soil Pollut., 223, 3125-3136 (2012) 
[18]N. Roongtanakiat, S. Tangruangkiat and R. Meesat, Utilization of vetiver grass (Vetiveria zizanioides) for removal of heavy metals from industrial wastewaters, Science Asia, 33, 397-403 (2007)

[19]N. Darajeh, A. Idris, P. Truong, A.A. Aziz, R.A Bakar and H.C. Man, Phytoremediation potential of vetiver system technology for improving the quality of palm oil mill effluent, Adv. Mater. Sc. Eng., 4 (2014)

[20]I. Raskin, R.D. Smith and D.E. Salt, Phytoremediation of metals: using plants to remove pollutants from the environment, Curr. Opin. Biotechnol., 8, 221-226 (1997)

[21] S.S. Andra, R. Datta, D. Sarkar, S.K.M. Saminathan, C.P. Mullens and S.B.H. Bach, Analysis of phytochelatin complexes in the lead tolerant vetiver grass [Vetiveria zizanioides (L.)] using liquid chromatography and mass spectrometry, Environ. Pollut., 157, 2173-2183 (2009)

[22] S. Ladislas, C. Gérente, F. Chazarenc, J. Brisson and Y. Andrès, Performances of two macrophytes species in floating treatment wetlands for cadmium, nickel, and zinc removal from urban stormwater runoff, Water, Air, Soil Pollut., 224, 1408 (2013) 